\title{
3D-QSAR, ADMET and Molecular Docking Study of a Series of 2-Substituted 1H-Benzimidazole-4-Carboxamide Derivatives Inhibitors Against Enteroviruses
}

\author{
Nidal Naceiri Mrabti ${ }^{1}$, Hanae Naceiri Mrabti ${ }^{2}$ (D), Mouna Mekkaoui ${ }^{3}$ (D), Jamal Sayah ${ }^{4}$, \\ Yassir El Ouadi ${ }^{5}$ (D), Mohamed Er-rajy ${ }^{6}$, Abdelhakim Bouyahya ${ }^{7, *}$ (D), Menana Elhallaoui ${ }^{1}$
}

1 Computer chemistry and modeling team, Laboratory of Materials, Modeling and Environmental Engineering, LIMME, Faculty of Sciences Dhar El Mehraz, Sidi Mohammed Ben Abdellah University, USMBA, BP.1796, 30000, Atlas, Fez. Morocco

2 Laboratory of Pharmacology and Toxicology, Bio Pharmaceutical and Toxicological Analysis Research Team, Faculty of Medicine and Pharmacy, Mohammed V University in Rabat, BP 6203, Rabat, Morocco

3 Pharmacodynamics Research Team, Laboratory of Pharmacology and Toxicology, Faculty of Medicine and Pharmacy, University Mohammed V in Rabat, Morocco

4 Laboratory of Applied Analytical Chemistry, Materials and Environment (LC2AME), Faculty of Sciences, Mohamed $1^{\text {st }}$ University, B.P.717, 60000, Oujda, Morocco

5 Laboratory of Applied Analytical Chemistry, Materials and Environment (LCA2ME), Faculty of Sciences, University Mohammed Premier, Oujda, Morocco

6 Engineering Materials, Modeling and Environmental Laboratory, Faculty of Science, University Sidi Mohammed Ben Abdellah, Dhar Mehraz, B.P. 1796, Atlas, Fes, Morocco

7 Laboratory of Human Pathologies Biology, Department of Biology, Faculty of Sciences, and Genomic Center of Human Pathologies, Faculty of Medicine and Pharmacy, Mohammed V University in Rabat, Morocco

* Correspondence: a.bouyahya@um5r.ac.ma; boyahyaa-90@hotmail.fr (A.B.);

Scopus Author ID 57190813643

Received: 10.10.2021; Revised: date; Accepted: date; Published: date

Abstract: A series of bioactive benzimidazoles were theoretically evaluated for their effect against enteroviruses, particularly coxsackievirus B and coxsackievirus A16. The structure-activity relationship allowed to deduce a very efficient model that can be used as a reference for the synthesis of compounds against this type of virus. The model used is essentially based on the RML and NN method, and its validation was carried out using cross-validation. The results obtained by molecular docking and ADMET of compound 9 as an inhibitor of enterovirus A16 give the proposal of the drug of this series.

Keywords: QSAR; MLR; neural network; cross-validation; ADMET; molecular docking.

(C) 2021 by the authors. This article is an open-access article distributed under the terms and conditions of the Creative Commons Attribution (CC BY) license (https://creativecommons.org/licenses/by/4.0/).

\section{Introduction}

Benzimidazole is a heterocyclic aromatic organic compound that has been an important pharmacophore and a preferred structure in medicinal chemistry [1]. Substituted benzimidazoles are of considerable interest as compounds with a broad spectrum of biological activities and low toxicities [2]. Antibiotics have saved the lives of millions of people. However, the dramatic increase in drug-resistant microbes threatens to reverse the medical progress of the past 50 years [3]. Benzimidazoles are highly effective compounds in terms of their bacterial inhibitory activity [4]. Some benzimidazole compounds inhibit the biosynthesis of ergosterol, which is required for the cell membrane of fungi and protozoa and is a useful target for antifungal drugs [5]. The result of numerous efforts to develop new molecules for effective antimicrobials has revealed that benzimidazoles remain one of the most versatile 
classes of compounds against microbes due to their potent relationship with DNA; hence the benzimidazole unit has become a promoter in the synthesis of a wide selection of drugs by targeting DNA and DNA-related processes [6]. The benzimidazole unit has the capacity to interact with enzymes binding to DNA, including DNA polymerase, RNA polymerase, and DNA topoisomerases I and II.

Enteroviruses can induce several such as gastroenteritis, myocarditis, and aseptic meningitis [7]. Human enteroviruses are widespread worldwide, excreted at high concentrations in human waste from infected individuals, and persistent in the environment [8]. By convention, enteroviruses have been classified into poliovirus, coxsackievirus A, coxsackievirus B, echovirus, and enterovirus 68-71 (EV 68-71) [9].

The coxsackievirus A16 (CVA16), a non-enveloped single-stranded RNA picornavirus belonging to the Picornaviridae family, is responsible for HFMD, which affects hands, feet, and mouth acting on infants young and children [10,11]. Furthermore, CVA16 interacts with

other enteroviruses such as enterovirus 71 (EV71), which is a major pathogen of hemorrhagic fever, resulting in severe clinical outcomes and viral genetic recombination $[12,13]$. Coxsackievirus B3 (CVB3) is an important human pathogen that induces acute and chronic viral myocarditis in children and young adults, pericarditis, and hepatitis [14]. Quantitative structure-activity-property relationships are tools to estimate physicochemical and biochemical parameters and reduce cost, time, and effort. QSAR/QSPR is an important section of computational chemistry and is frequently used to predict organic compounds' physicochemical and biological activities. Mathematical methods can be used to establish the relationship between the molecule's structural characteristics and its activity [15]. A large number of molecular descriptors are available for use in QSAR studies [16].

The objective of this work is to determine a quantitative structure-activity relationship of benzimidazole derivatives against Coxsackie B3 virus in VERO cells by studying a series of 39 compounds of 2-substituted -1H-Benzimidazole-4-carboxamide derivatives, and based on the predicted model to do molecular docking with the most active and least toxic compound with enterovirus A16 [17]. As a result, a quantitative model is proposed with an interpretation of the activity of the compound using statistical analysis. The artificial neural network (ANN) is based on the selected descriptors used as input parameters in the multiple linear regression (MLR). These results are evaluated by the cross-validation method with the LOO procedure.

\section{Materials and Methods}

\subsection{Experimental data.}

The structure of the 2- substituted-1 H-benzimidazole-4-carboxamide is represented in Figure 1.

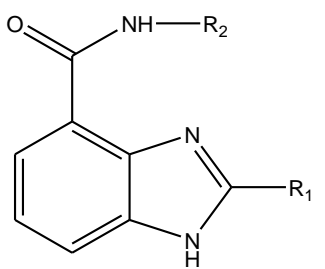

Figure 1. The general structure of the benzimidazole derivatives.

The experimental activities observed $\mathrm{TC}_{50}$ and $\mathrm{IC}_{50}$ are collected from recent publications $[13,15]$. Observations are converted into logarithmic scale $\log \mathrm{IC}_{50}$ and $\log \mathrm{TC}_{50}$ and are included in Table 1. 
Table 1. Structure and activity of benzimidazole derivatives against Coxsackievirus B3 in VERO cells.

\begin{tabular}{|c|c|c|c|c|}
\hline Compounds & $\mathbf{R}_{1}$ & $\mathbf{R}_{\mathbf{2}}$ & IC $_{50 \mathrm{EXP}}$ & TC $_{50 \mathrm{EXP}}$ \\
\hline 1 & 4-methylpyridine & 1-chloro-4-methylbenzene & 8.72 & 20.45 \\
\hline 2 & 4-methylpyridine & 1-bromo-3-methylbenzene & 4.12 & 8.24 \\
\hline 3 & 4-methylpyridine & o-xylene & 2.23 & 10.74 \\
\hline 4 & 4-methylpyridine & 1-methyl-4-nitrobenzene & 18.52 & 55.50 \\
\hline 5 & 4-methylpyridine & m-cresol & NT & 5.90 \\
\hline 6 & 4-methylpyridine & o-cresol & 4.05 & 18.50 \\
\hline 7 & 2-methylpyridine & $\mathrm{H}$ & 30.60 & 224.00 \\
\hline 8 & 2-methylpyridine & propan-1-ol & 131.00 & 568.00 \\
\hline 9 & 2-methylpyridine & $\begin{array}{l}\text { 2-methyl-1-(4-nitrophenyl)propane- } \\
\text { 1,3-diol }\end{array}$ & 4.06 & 1332.00 \\
\hline 10 & 2-methylpyridine & Toluene & 0.46 & 17.90 \\
\hline 11 & 2-methylpyridine & 1-fluoro-2-methylbenzene & 1.63 & 54.70 \\
\hline 12 & 2-methylpyridine & 2,4-dimethylthiazole & 1.76 & 17.70 \\
\hline 13 & 3-methylpyridine & $\mathrm{H}$ & 26.00 & 77.70 \\
\hline 14 & 3-methylpyridine & propan-1-ol & 90.70 & 682.00 \\
\hline 15 & 3-methylpyridine & $\begin{array}{l}\text { 2-methyl-1-(4-nitrophenyl)propane- } \\
\text { 1,3-diol }\end{array}$ & 28.60 & 148.00 \\
\hline 16 & 3-methylpyridine & Toluene & 3.72 & 34.20 \\
\hline 17 & 3-methylpyridine & 1-fluoro-2-methylbenzene & 9.73 & 54.70 \\
\hline 18 & 3-methylpyridine & 2,4-dimethylthiazole & 16.20 & 111.00 \\
\hline 19 & 4-methylpyridine & propan-1-ol & NT & 498.00 \\
\hline 20 & 4-methylpyridine & $\begin{array}{l}\text { 2-methyl-1-(4-nitrophenyl)propane- } \\
\text { 1,3-diol }\end{array}$ & 30.20 & 123.00 \\
\hline 21 & 4-methylpyridine & Toluene & 12.30 & 49.80 \\
\hline 22 & 4-methylpyridine & 1-fluoro-2-methylbenzene & 37.20 & 111.00 \\
\hline 23 & 4-methylpyridine & 2,4-dimethylthiazole & 21.30 & 111.00 \\
\hline 24 & 2-methylfuran & 1-fluoro-2-methylbenzene & 3.30 & 25.00 \\
\hline 25 & 2-methylfuran & $\begin{array}{l}\text { 2-methyl-1-(4-nitrophenyl)propane- } \\
\text { 1,3-diol }\end{array}$ & 37.70 & 152.00 \\
\hline 26 & 2-methylfuran & $\begin{array}{l}\text { 1-(4-chlorophenyl)-2-methylbutan-1- } \\
\text { ol }\end{array}$ & 13.40 & 162.00 \\
\hline 27 & 2-methyl-5-nitrofuran & 1-fluoro-2-methylbenzene & 25.30 & 75,90 \\
\hline 28 & 2-methyl-5-nitrofuran & $\begin{array}{l}\text { 2-methyl-1-(4-nitrophenyl)propane- } \\
\text { 1,3-diol }\end{array}$ & 22.90 & 68,70 \\
\hline 29 & 2-methyl-5-nitrofuran & $\begin{array}{l}\text { 1-(4-chlorophenyl)-2-methylbutan-1- } \\
\text { ol }\end{array}$ & 16,20 & 48,60 \\
\hline 30 & $\begin{array}{l}\text { 1,2-dimethoxy-4- } \\
\text { methylbenzene }\end{array}$ & 1-fluoro-2-methylbenzene & 3,50 & 24,50 \\
\hline 31 & $\begin{array}{l}\text { 1,2-dimethoxy-4- } \\
\text { methylbenzene }\end{array}$ & propan-1-ol & 17,20 & 46,00 \\
\hline 32 & $\begin{array}{l}\text { 1,2-dimethoxy-4- } \\
\text { methylbenzene }\end{array}$ & 3-methylpentane & 0.70 & 2.23 \\
\hline 33 & $\begin{array}{l}\text { 1,2-dimethoxy-4- } \\
\text { methylbenzene }\end{array}$ & 2-chloro-5-methylpyrazine & 18.40 & 78.30 \\
\hline 34 & $\begin{array}{l}\text { 1,2,3-trimethoxy-4- } \\
\text { methylbenzene }\end{array}$ & 1-fluoro-2-methylbenzene & 9.80 & 37.80 \\
\hline 35 & $\begin{array}{l}\text { 1,2,3-trimethoxy-4- } \\
\text { methylbenzene }\end{array}$ & $\begin{array}{l}\text { 2-methyl-1-(4-nitrophenyl)propane- } \\
\text { 1,3-diol }\end{array}$ & 4.73 & 9.85 \\
\hline 36 & $\begin{array}{l}\text { 1,2,3-trimethoxy-4- } \\
\text { methylbenzene }\end{array}$ & propan-1-ol & 19.50 & 40.00 \\
\hline 37 & $\begin{array}{l}\text { 1,2,3-trimethoxy-4- } \\
\text { methylbenzene }\end{array}$ & 3-methylpentane & 18.70 & 32.30 \\
\hline 38 & $\begin{array}{l}\text { 1,2,3-trimethoxy-4- } \\
\text { methylbenzene }\end{array}$ & 2-chloro-5-methylpyrazine & 17.40 & 65.20 \\
\hline 39 & $\begin{array}{l}\text { 1,2,3-trimethoxy-4- } \\
\text { methylbenzene }\end{array}$ & $\begin{array}{l}\text { 1,7a-dihydro-2-methyl-2H- } \\
\text { benzo[d]imidazole }\end{array}$ & 16.90 & 29.00 \\
\hline
\end{tabular}

\subsection{Descriptors generation.}

All the molecules were designed and pre-optimized in the ACDLAB 12.0 program using an MM2 force field. Then, the calculation of steric, thermodynamic, and electronic descriptors was done by Chem3D Ultra software (Table 2). 
Table 2. Various descriptors chosen for the QSAR model.

\begin{tabular}{l|l}
\hline Descriptors generation & $\begin{array}{l}\text { Steric, thermodynamic, and topologic } \\
\text { chemical }\end{array}$ \\
\hline All molecules were drawn and pre- & Cluster Count (Cls) \\
optimized in the ACDLAB.12.0 & Molecular Weight(MW) \\
program using an MM2 force field. & Cluster Count (ClsC) \\
Then, steric, thermodynamic and & Wiener Index (Windx) \\
electronic descriptors were calculated & Parachor (Par) \\
by Chem3D Ultra software. (Table 2). & Balban Index (Blndx) \\
& Molecular Topological Index (TIndx) \\
& Lypophilie (LogP) \\
& Molecular Refraction( RM) \\
& Henry's law constant (H) \\
& Heat of Formation (HF) \\
& VDW Energy (EvDw) \\
& Torsion Energy(Et)
\end{tabular}

\subsection{Multiple linear regression (MLR).}

The QSAR model is developed using the standard method of multivariate data analysis, multiple linear regression (MLR) [22]. It is also called ordinary least squares regression (OLS) [23]. Thus, MLR estimates the values of the regression coefficients by applying the leastsquares curve fitting method [24]. The regression equation is in the following form:

$$
Y_{M L R}=a_{\mathrm{o}}+\sum_{i=1}^{n} a_{i} \times C_{i}
$$

Or YMLR: dependent variable; $\mathrm{a}_{0}$ : regression constant or intercept; $\mathrm{a}_{\mathrm{i}}$ : regression coefficient; $\mathrm{C}_{\mathrm{i}}$ : independent variable.

The multiple linear regression (MLR) model was used to select the descriptors used as input parameters for a back-propagation network (NN).

The neural network (NN) is capable of creating internal models for complex inputoutput relationships based on learning from examples and is therefore useful for prediction[25]. All feed-forward neural networks used in this paper are three-layer networks in which the input layer contains four neurons, representing the relevant descriptors obtained by MLR techniques. No theoretical or empirical rule exists to determine the number of hidden layers or the number of layers of neurons; however, One layer of neurons seems to be sufficient in most chemical applications of NNs [25,26]. Some authors have suggested a parameter $\rho$, which is used for determining the number of hidden neurons. It plays a big factor in determining the best architecture of NNs [11, 17].

This parameter is defined as follows:

$$
\rho=\frac{\text { Number of data points in the training set }}{\text { Sum of the number of connections in the NN }}
$$

To avoid overfitting or underfitting, it is advised that $1.8 \leq \rho \leq 2.3$ [16].

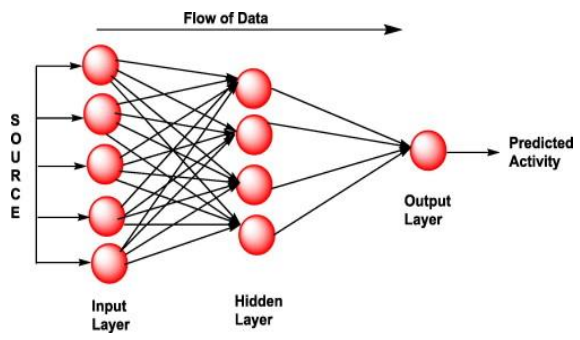

Figure 2. A simplified sketch for the artificial neural network structure. 


\subsection{Cross-validation.}

A statistical method divides the data into two groups, one for training and the other for model validation[28]. The training data allows estimating the model while the validation data allows measuring its fit error on the data [29]. There are several variants of cross-validation; we are interested in one of them, called LOOCV (Leave-one-Out Cross Validation) [30] . The correlation coefficient $r$ has the following expression:

$$
\mathrm{r}=1-\frac{\sum\left(\mathrm{Y}_{\text {pred }}-\mathrm{Y}_{\mathrm{exp}}\right)^{2}}{\sum\left(\mathrm{Y}_{\mathrm{exp}}-\mathrm{Y}_{\text {mean }}\right)^{2}}
$$

where $Y_{\text {pred }}, Y_{\text {exp }}$ and $Y_{\text {mean }}$ are the values for the predicted activity, experimental activity, and mean activity, respectively.

\subsection{ADMETlab Study.}

ADMETlab 2.0, a free web service, was used to predict the physicochemical, medicinal chemistry, toxicity, absorption, distribution, metabolism, and excretion study of the active and the reference molecules to judge the development of new drug (http://admetmesh.scbdd.com/service/screening/molecule) [31]. ADMETlab module was run to obtain the quantitative estimates of drug-likeness, For the classification endpoints, the prediction probability values are transformed into six symbols: 0-0.1(---), 0.1-0.3(--), 0.3-0.5(), 0.5-0.7(+), 0.7-0.9(++), and 0.9-1.0(+++). ADMETlab 2.0 allows the evaluation of single molecules and batches, whose input parameters and output information will be developed respectively. [32].

The evaluation model offers two approaches to molecule submission: paste the SMILES string or draw the chemical structure using the JMSE molecule editor (A). Once a user submits the work, the webserver standardizes the input SMILES strings and calculates all endpoints. The prediction results are shown in tabular form in the browser, with the 2D molecular structure and a radar graph summarizing the physicochemical quality of the compound. Concrete predictive values are given for the parameters predicted by the regression models, like Caco-2 permeability, plasma protein binding, etc. [33].

The substructural rules available in the webserver, such as PAINS, SureChEMBL Rule, etc., were implemented using the SMARTS recognition capability of the RDKit function. And the calculation of physicochemical and medicinal chemistry endpoints was based on the python library Scopy (B), following the parameters reported in corresponding original papers strictly. If the number of alerts is not zero, users can click the DETAIL button to check the undesirable substructures in the molecule. Finally, the full result file can be downloaded in CSV or PDF format [34].

\subsection{Molecular docking.}

Docking is, therefore, a very useful tool in biology, pharmacy, and medicine, as most active ingredients are small molecules (ligands) that interact with a biological target of therapeutic interest, usually a protein (receptor), in order to influence the mechanism in which this protein is involved [35] [36]. Docking remains an important step in understanding biological reactions and, consequently, drug design. Docking approaches are based on the "key-lock" concept [24]. The ligand (the most active molecule) is designed using Chemdraw8.0 
software. Optimization of the ligand geometry was performed using the force field (MM+) to determine the most stable conformation. The elimination of water molecules and cocrystallization inhibitors allows us to obtain a simplified protein model [37].

The molecular docking study was performed with an extensible program to visualize and analyze molecular structures, which is UCSF Chimera. Optimization of the protein geometry (5FOQ) was performed using the AMBERff03.r1 force field and AutoDock Vina energy calculations implemented in UCSF Chimera software (www.cgl.ucsf.edu/chimera). AutoDock Vina, a molecular docking and virtual screening program, allows ligand-receptor calculations to execute [38]. Vina uses a gradient optimization method in his local optimization procedure $[39,40]$. It gives the optimization algorithm for a single evaluation and simulation program for docking a flexible ligand to a rigid receptor. This work studies the interactions between the most active molecule (compound 9) and the protein.

\section{Results and Discussion}

\subsection{Statistical analysis.}

A QSAR study was performed for a series of 39 benzimidazole derivatives to identify a quantitative relationship between structure and potential anti-enterovirus activities. The results of this 3D QSAR study using MLR, NN, and CV methods are represented in Table 3.

Table 3. Observed and predicted comparative activities of statistically significant patterns obtained by the 3D

\begin{tabular}{|c|c|c|c|c|c|c|c|c|c|c|}
\hline Compounds & IC $_{50 \mathrm{EXP}}$ & Log IC & $\begin{array}{c}\operatorname{LogIC}_{50} \\
\text { RLM }\end{array}$ & $\operatorname{LogIC} C_{50 R N}$ & $\operatorname{LogIC}_{50 \mathrm{VC}}$ & T C 50EXP & $\operatorname{LogTC}_{50 \mathrm{EXP}}$ & $\operatorname{LogTC}_{50 R L M}$ & $\log ^{T} C_{50 R N}$ & $\operatorname{LogTC}_{50 \mathrm{~V} C}$ \\
\hline 1 & 8.7200 & 0.9405 & 0.6606 & 0.8255 & 0.9986 & 20.4500 & 1.3107 & 1.2949 & 1.2056 & 1.4444 \\
\hline 2 & 4.1200 & 0.6149 & 0.9096 & 0.8009 & 0.9362 & 8.2400 & 0.9159 & 1.2355 & 0.7563 & 0.9561 \\
\hline 3 & 2.2300 & 0.3483 & 0.0104 & 0.4234 & 0.3736 & 10.7400 & 1.0310 & 1.1336 & 1.1808 & 1.1806 \\
\hline 4 & 18.5200 & 1.2676 & 0.8801 & 0.9450 & 1.0798 & 55.5000 & 1.7443 & 1.7980 & 1.8542 & 1.7832 \\
\hline 5 & NT & NT & NT & NT & NT & 5.9000 & 0.7709 & 0.7476 & 0.5705 & 0.7668 \\
\hline 6 & 4.0500 & 0.6075 & 0.5565 & 0.8697 & 0,8719 & 18.5000 & 1.2672 & 1.6089 & 1.5758 & 1.3406 \\
\hline 7 & 30.6000 & 1.4857 & 1.4745 & 1.6251 & 1.5473 & 224.0000 & 2.3502 & 2.0903 & 2.3564 & 2.5018 \\
\hline 8 & 131.0000 & 2.1173 & 2.2038 & 2.2020 & 2.3132 & 568.0000 & 2.7543 & 2.2143 & 2.4162 & 2.3823 \\
\hline 9 & 4.0600 & 0.6085 & 0.2707 & 0.5775 & 0.9245 & 1332.0000 & 3.1245 & 2.3284 & 2.7939 & 2.1822 \\
\hline 10 & 0.4590 & -0.3382 & 0.3340 & -0.0393 & -0.2244 & 17.9000 & 1.2529 & 1.5982 & 1.5381 & 1.5302 \\
\hline 11 & 1.6300 & 0.2122 & 0.6389 & 0.3394 & 0.4501 & 54.7000 & 1.7380 & 1.6617 & 1.7014 & 1.6342 \\
\hline 12 & 1.7600 & 0.2455 & 0.6321 & 0.2529 & 0.1215 & 17.7000 & 1.2480 & 1.7862 & 1.2850 & 1.7473 \\
\hline 13 & 26.0000 & 1.4150 & 1.3178 & 1.3548 & 1.3456 & 77.7000 & 1.8904 & 2.0099 & 2.0406 & 2.2091 \\
\hline 14 & 90.7000 & 1.9576 & 1.5509 & 1.6788 & 1.5768 & 682.0000 & 2.8338 & 2.5126 & 3.0431 & 2.2527 \\
\hline 15 & 28.6000 & 1.4564 & 1.6779 & 1.7474 & 1.4325 & 148.0000 & 2.1703 & 2.2238 & 2.3841 & 2.2086 \\
\hline 16 & 3.7200 & 0.5705 & 0.6678 & 0.6579 & 1.3734 & 34.2000 & 1.5340 & 1.6584 & 1.5616 & 1.5831 \\
\hline 17 & 9.7300 & 0,9881 & 0.7816 & 0.7260 & 0.7784 & 54.7000 & 1.7380 & 1.5794 & 1.5550 & 1.7361 \\
\hline 18 & 16.2000 & 1,2095 & 1.1843 & 1.2242 & 1.2683 & 111.0000 & 2.0453 & 1.7075 & 1.6322 & 1.6970 \\
\hline 19 & NT & NT & NT & NT & NT & 498.0000 & 2.6972 & 2.4169 & 2.6058 & 2.6135 \\
\hline 20 & 30.2000 & 1.4800 & 1.4746 & 1.6112 & 1.4571 & 123.0000 & 2.0899 & 2.0217 & 1.9981 & 2.0822 \\
\hline 21 & 12.3000 & 1.0899 & 0.9308 & 0.7189 & 1.0271 & 49.8000 & 1.6972 & 1.7843 & 1.6873 & 1.6907 \\
\hline 22 & 37.2000 & 1.5705 & 1.4259 & 1.4429 & 1.9767 & 111.0000 & 2.0453 & 1.5991 & 1.5833 & 1.9418 \\
\hline 23 & 21.3000 & 1.3284 & 1.5070 & 1.3580 & 1,5021 & 111.0000 & 2.0453 & 2.3751 & 2.1644 & 2.1723 \\
\hline 24 & 3.3000 & 0.5185 & 0.6406 & 0.6212 & 0.4111 & 25.0000 & 1.3979 & 1.3234 & 1.4604 & 1.0049 \\
\hline 25 & 37.7000 & 1.5763 & 2.0838 & 1.4890 & 1.7795 & 152.0000 & 2,1818 & 2.1337 & 2.3265 & 2.2391 \\
\hline 26 & 13.4000 & 1.1271 & 1.1322 & 1.0728 & 1.1439 & 162.0000 & 2.2095 & 2.1822 & 2.2376 & 2.2225 \\
\hline 27 & 25.3000 & 1.4031 & 1.7626 & 1.6198 & 1.8219 & 75.9000 & 1.8802 & 2.0897 & 2.0020 & 1.8792 \\
\hline 28 & 22.9000 & 1.3598 & 1.6296 & 1.4039 & 1.3555 & 68.7000 & 1.8370 & 1.9250 & 1.6482 & 2.0081 \\
\hline 29 & 16.2000 & 1.2095 & 0.9661 & 1.0568 & 0.9645 & 48.6000 & 1.6866 & 1.9155 & 1.6618 & 1.8239 \\
\hline
\end{tabular}




\begin{tabular}{|c|c|c|c|c|c|c|c|c|c|c|}
\hline Compounds & IC IC $_{50 \mathrm{EXP}}$ & Log IC F0EXP & $\begin{array}{c}\operatorname{LogIC} C_{50} \\
\text { RLM }\end{array}$ & $\operatorname{LogIC}_{50 \mathrm{RN}}$ & $\operatorname{LogIC}_{50 \mathrm{VC}}$ & T C 50EXP & $\operatorname{LogTC}_{50 \mathrm{EXP}}$ & $\operatorname{LogTC}_{50 R L M}$ & $\operatorname{LogTC}_{50 \mathrm{RN}}$ & $\operatorname{LogTC}_{50 \mathrm{VC}}$ \\
\hline 30 & 3.5000 & 0.5441 & 0.4676 & 0.4626 & 0.4792 & 24.5000 & 1.3892 & 1.2583 & 1.4624 & 1.4187 \\
\hline 31 & 17.2000 & 1.2355 & 0.9539 & 0.9757 & 1.1981 & 46.0000 & 1.6628 & 1.8260 & 1.6812 & 1.5970 \\
\hline 32 & 0.7000 & -0.1549 & -0.2027 & $-0,0398$ & -0.1252 & 2.2300 & 0.3483 & 1.0844 & 0.6236 & 1.3724 \\
\hline 33 & 18.4000 & 1.2648 & 1.2872 & 1.2534 & 1.1799 & 78.3000 & 1.8938 & 1.9459 & 1.7930 & 1.8739 \\
\hline 34 & 9.8000 & 0.9912 & 0.7504 & 0.8886 & 0.9289 & 37.8000 & 1.5775 & 1.3428 & 1.4858 & 1.3636 \\
\hline 35 & \begin{tabular}{|l|}
4.7300 \\
\end{tabular} & 0.6749 & 0.8458 & 0.7070 & 0.9224 & 9.8500 & 0.9934 & 1.2266 & 1.4383 & 1.6459 \\
\hline 36 & \begin{tabular}{|l|}
19.5000 \\
\end{tabular} & 1.2900 & 1.1793 & 1.2830 & 1.1671 & 40.0000 & 1.6021 & 1.8182 & 1.6906 & 1.8005 \\
\hline 37 & 18.7000 & 1.2718 & 0.9128 & 1.4745 & 1.4532 & 32.3000 & 1.5092 & 1.0961 & 1.3806 & 1.2377 \\
\hline 38 & \begin{tabular}{|l|}
17.4000 \\
\end{tabular} & 1.2405 & 1.3033 & 1.3190 & 1.2147 & 65.2000 & 1.8142 & 1.9052 & 1.9213 & 1.8364 \\
\hline 39 & \begin{tabular}{|l|}
16.9000 \\
\end{tabular} & 1.2279 & 1.0684 & 1.0758 & 1.1535 & 29.0000 & 1.4624 & 1.3508 & 1.4318 & 1.3590 \\
\hline 40 & \begin{tabular}{|l|}
1690.0000 \\
\end{tabular} & 3.2279 & 2.6890 & 3.2137 & 2.0825 & 8190.0000 & 3.9133 & 4.2569 & 3.9191 & 3.2884 \\
\hline
\end{tabular}

The dataset comprising the 39 molecules and 19 descriptors is subjected to stepwise multiple regression analysis to propose an MLR model.

We proposed two models: the first one presents the $\mathrm{IC}_{50}$ activity and its relation with the molecular descriptors, and the second one presents the $\mathrm{TC}_{50}$ toxicity in relation to the same molecular descriptors. This method used the $\mathrm{r}, \mathrm{r}^{2}$, and $\mathrm{t}$-values to choose the best regression result. Figures 2 and 3 show the MLR results, which include the coefficients of the corresponding normalized descriptors and the correlation between observed and predicted activities. In addition, the two QSAR models of the constructed training set are represented by the following two equations (4) and (5).

$$
\begin{gathered}
\operatorname{LogIC}_{50}=-2,850+2,684 d+0,267 \mathrm{E}_{\mathrm{LUMO}}-0,115 \log \mathrm{P}+0,165 \mathrm{VDW} \text { (4) } \\
\qquad \mathrm{n}=41 ; \mathrm{r}=0,901 ; \mathrm{r}^{2}=0,811 ; \mathrm{sd}=0,291 ; \mathrm{F}=48,633
\end{gathered}
$$

$$
\begin{gathered}
\operatorname{LogTC}_{50 \mathrm{RLM}}=-2,192+0,514 \mathrm{E}_{\mathrm{LUMO}}-0,218 \log \mathrm{P}+0,268 \mathrm{VDW}+0,034 \mathrm{ST}(5) \\
\mathrm{n}=39, \mathrm{r}=0,89 ; \mathrm{r}^{2}=0,79 ; \mathrm{sd}=0,334 \mathrm{~F}=16,756
\end{gathered}
$$

where

$\mathrm{n}$ : the number of compounds

$\mathrm{r}$ : the correlation coefficient

$\mathrm{r}^{2}$ is the Squared Multiple

$\mathrm{Sd}$ is the standard deviation

$\mathrm{F}$ is the Fisher F-statistic.

According to model 3, four descriptors correlated with $\mathrm{Log}_{\mathrm{IC}} \mathrm{IC}_{50}$ (the median inhibitory concentration) $\left(\mathrm{r}^{2}=0.811\right)$; density $(\mathrm{d})$, LUMO Energy $\left(\mathrm{E}_{\mathrm{LUMO}}\right)$, partition coefficient $(\log \mathrm{P})$, and $E_{V D w}$ energy. The normalization diagram of the coefficients (Figure 4) showed that three descriptors acted positively on $\log \mathrm{IC}_{50}$ by decreasing the activity of the molecule; they are the $\mathrm{d}, \mathrm{E}_{\mathrm{LUMO}}$, and $\mathrm{E}_{\mathrm{VDW}}$, while a relationship of antagonism is registered between $\log \mathrm{P}$ and $\log \mathrm{IC}_{50}$. In fact, density is the factor most acting on the molecule's activity, with a coefficient of 2.684. Indeed, when atoms composing a molecule have a high molecular weight, their density is important, and, therefore, the molecule will be less active.

On the other hand, LUMO energy has a positive effect on $\log \mathrm{IC}_{50}$ and VDW with coefficients of 0.267 and 0.165 , respectively. The energy LUMO (Lowest Unoccupied Molecular Orbital) Translates the electro-acceptor character of the molecule. The lower the energy of this $\mathrm{MO}$, the more easily the molecule will accept electrons. 


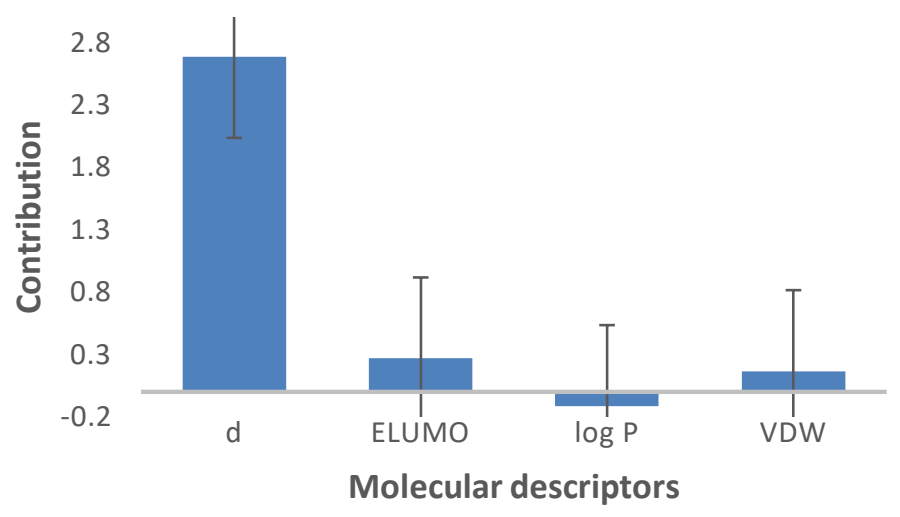

Figure 3. Modeling characterization by the normalized coefficients of $\log \mathrm{IC}_{50}$.

In addition, the partition coefficient $(\log \mathrm{P})$ correlated negatively with $\mathrm{IC}_{50}$; this generates the increase of the biological activity in parallel with Log P.

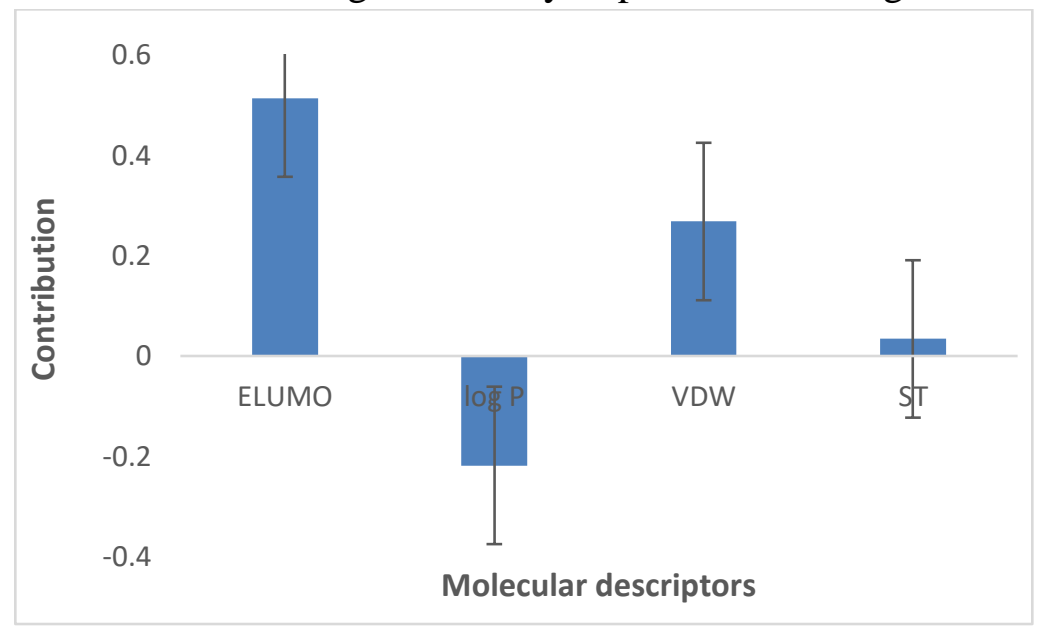

Figure 4. Modeling characterization by the normalized coefficients of log TC50

Toxicity is related to four descriptors, three of which also influenced the activity, namely $E_{\text {LUMO }}, \operatorname{LogP}$, and EVDw. Surface tension (ST) is a new parameter detected in model 4, it has a relation to intermolecular attraction forces, so the stronger the intermolecular forces, the tighter the molecules are together.

According to Figure 5, the toxicity is strongly influenced by $\mathrm{E}_{\mathrm{LUMO}}$ positively and Log $P$ negatively; however, the surface tension exerted a very weak effect.

The three methods used, MRL, NN, and CV, recorded similar Log $\mathrm{IC}_{50}$ values between 0.5 and 1.5. However, statistical analysis showed that the NN method was significantly closer to the experiment $\left(\mathrm{R}^{2}=0.93\right)$ regardless of the $\log \mathrm{IC}_{50}$ value. Both activity and toxicity models were validated by the $\mathrm{CV}$ method. They recorded coefficients of $\mathrm{R}^{2}=0.79$ and $\mathrm{R}^{2}=0.76$ respectively (Figure 6 and Figure 7) hence the effectiveness of the predicted statistical model.

The selectivity index (SI) represents the ratio between $\mathrm{TC}_{50}$ and $\mathrm{IC}_{50}$; it increases proportionally with the increase of $\mathrm{TC}_{50}$ and the decrease of $\mathrm{IC}_{50}$. This parameter is an indicator of the choice of the most efficient molecule (Figure 8). In our case, molecule 9 has the highest SI, it is therefore the most effective compared to RBV (Table 4). Figure 8 proves the results deduced from Figure 6 and Figure 7; the NN method recorded the closest selectivity indices to the experiment. 


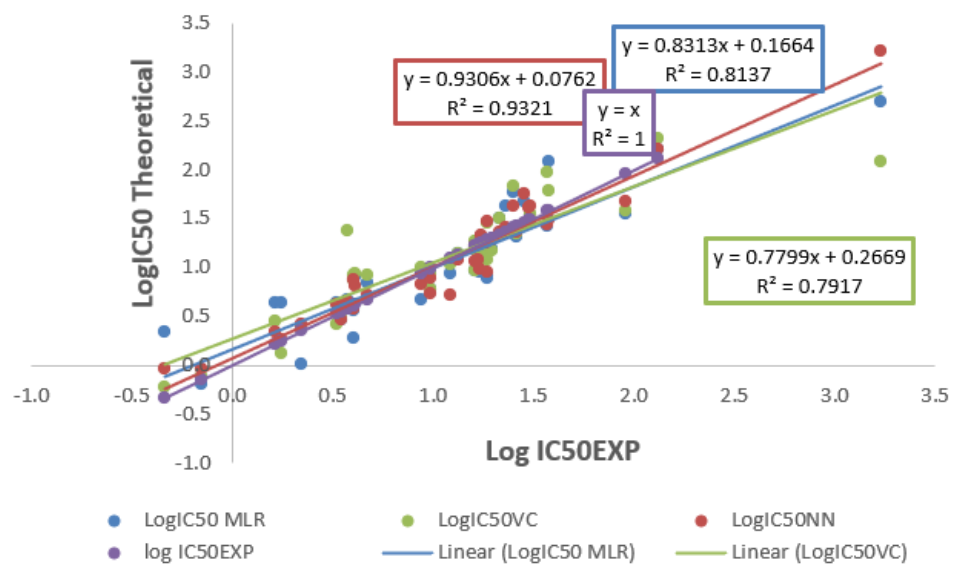

Figure 5. Predicted inhibitory enterovirus activities by MLR, NN, and CV correlated to experimental activity values.
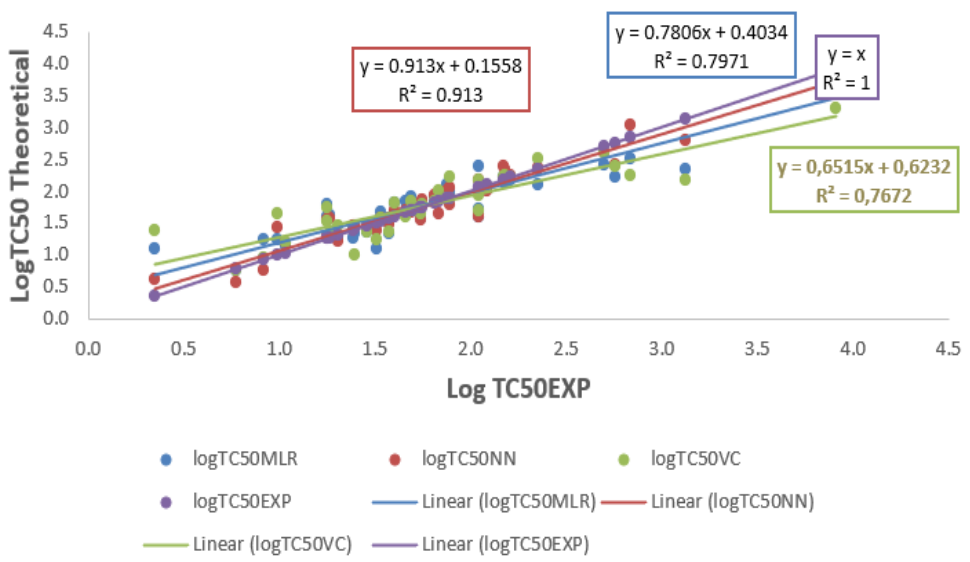

Figure 6. Predicted inhibitory enterovirus activities by MLR, NN, and CV correlated to experimental toxicity values.

Table 4. Comparative observed and predicted selectivity index of each compound, used statistical methods

\begin{tabular}{|c|c|c|c|c|c|c|}
\hline \multirow[b]{2}{*}{ Compounds } & \multicolumn{4}{|c|}{ MLR and NN. } & \multirow[b]{2}{*}{$\begin{array}{ll}\text { Log } & \text { SI } \\
\text { RLM } & \end{array}$} & \multirow[b]{2}{*}{$\mid \begin{array}{l}\log \text { SI } \\
\text { NN }\end{array}$} \\
\hline & SI EXP & SI RLM & $\mathbf{S I}_{\mathrm{NN}}$ & $\begin{array}{l}\text { Log SI } \\
\text { EXP }\end{array}$ & & \\
\hline 1 & 2,3500 & 4,3073 & 2,3994 & 0,3711 & 0,6342 & 0,3801 \\
\hline 2 & 2,0000 & 2,1176 & 0,9024 & 0,3010 & 0,3258 & $-0,0446$ \\
\hline 3 & 11,4800 & 13,2795 & 5,7201 & 1,0599 & 1,1232 & 0,7574 \\
\hline 4 & 2,9900 & 8,2771 & 8,1133 & 0,4757 & 0,9179 & 0,9092 \\
\hline 5 & NT & NT & NT & NT & NT & NT \\
\hline 6 & 4,5600 & 11,2812 & 5,0828 & 0,6590 & 1,0524 & 0,7061 \\
\hline 7 & 7,3000 & 4,1281 & 5,3864 & 0,8633 & 0,6158 & 0,7313 \\
\hline 8 & 4,3000 & 1,0246 & 1,6376 & 0,6335 & 0,0106 & 0,2142 \\
\hline 9 & 328,0000 & 114,1949 & 164,5887 & 2,5159 & 2,0576 & 2,2164 \\
\hline 10 & 38,9000 & 18,3735 & 37,792 & 1,5899 & 1,2642 & 1,5774 \\
\hline 11 & 28,4000 & 10,538 & 23,0144 & 1,4533 & 1,0228 & 1,3620 \\
\hline 12 & 10,0000 & 14,2605 & 10,7671 & 1,0000 & 1,1541 & 1,0321 \\
\hline 13 & 3,0000 & 4,9212 & 4,8507 & 0,4771 & 0,6921 & 0,6858 \\
\hline 14 & 7,5000 & 9,1559 & 23,1366 & 0,8751 & 0,9617 & 1,3643 \\
\hline 15 & 5,2000 & 3,515 & 4,3321 & 0,7160 & 0,5459 & 0,6367 \\
\hline 16 & 9,2000 & 9,7857 & 8,0112 & 0,9638 & 0,9906 & 0,9037 \\
\hline 17 & 3,2000 & 6,2781 & 6,7453 & 0,5051 & 0,7978 & 0,8290 \\
\hline 18 & 6,8000 & 17,084 & 2,5586 & 0,8325 & 1,2326 & 0,4080 \\
\hline 19 & NT & NT & NT & NT & NT & NT \\
\hline 20 & 4,1000 & 3,5243 & 2,4372 & 0,6128 & 0,5471 & 0,3869 \\
\hline 21 & 4,0000 & 7,1362 & 9,2982 & 0,6021 & 0,8535 & 0,9684 \\
\hline
\end{tabular}




\begin{tabular}{|c|c|c|c|c|c|c|}
\hline Compounds & SI EXP & SI RLM & $\mathbf{S I}_{\mathbf{N N}}$ & $\begin{array}{l}\log \text { SI } \\
\text { EXP }\end{array}$ & $\begin{array}{ll}\text { Log } & \text { SI } \\
\text { RLM } & \end{array}$ & $\begin{array}{l}\log S I \\
\text { NN }\end{array}$ \\
\hline 22 & 3,0000 & 1,4899 & 1,3817 & 0,4771 & 0,1732 & 0,1404 \\
\hline 23 & 5,2000 & 7,3795 & 6,4032 & 0,7160 & 0,8680 & 0,8064 \\
\hline 24 & 7,5000 & 4,8169 & 6,9056 & 0,8751 & 0,6828 & 0,8392 \\
\hline 25 & 4,0000 & 1,1217 & 6,8786 & 0,6021 & 0,0499 & 0,8375 \\
\hline 26 & 12,1000 & 11,2214 & 14,615 & 1,0828 & 1,0500 & 1,1648 \\
\hline 27 & 3,0000 & 2,1236 & 2,411 & 0,4771 & 0,3271 & 0,3822 \\
\hline 28 & 3,0000 & 1,9744 & 1,7551 & 0,4771 & 0,2954 & 0,2443 \\
\hline 29 & 3,0000 & 8,9005 & 4,0272 & 0,4771 & 0,9494 & 0,6050 \\
\hline 30 & 7,0000 & 6,1761 & 9,9954 & 0,8451 & 0,7907 & 0,9998 \\
\hline 31 & 2,7000 & 7,4492 & 5,0757 & 0,4314 & 0,8721 & 0,7055 \\
\hline 32 & 3,0000 & 19,3729 & 4,6068 & 0,4771 & 1,2872 & 0,6634 \\
\hline 33 & 4,3000 & 4,5571 & 3,4642 & 0,6335 & 0,6587 & 0,5396 \\
\hline 34 & 3,9000 & 3,9121 & 3,9555 & 0,5911 & 0,5924 & 0,5972 \\
\hline 35 & 2,0000 & 2,4032 & 5,3864 & 0,3010 & 0,3808 & 0,7313 \\
\hline 36 & 2,1000 & 4,3547 & 2,5562 & 0,3222 & 0,6390 & 0,4076 \\
\hline 37 & 1,7000 & 1,525 & 0,8056 & 0,2304 & 0,1833 & $-0,0939$ \\
\hline 38 & 3,8000 & 3,9983 & 4,0022 & 0,5798 & 0,6019 & 0,6023 \\
\hline 39 & 1,7000 & 1,9161 & 2,2699 & 0,2304 & 0,2824 & 0,3560 \\
\hline
\end{tabular}

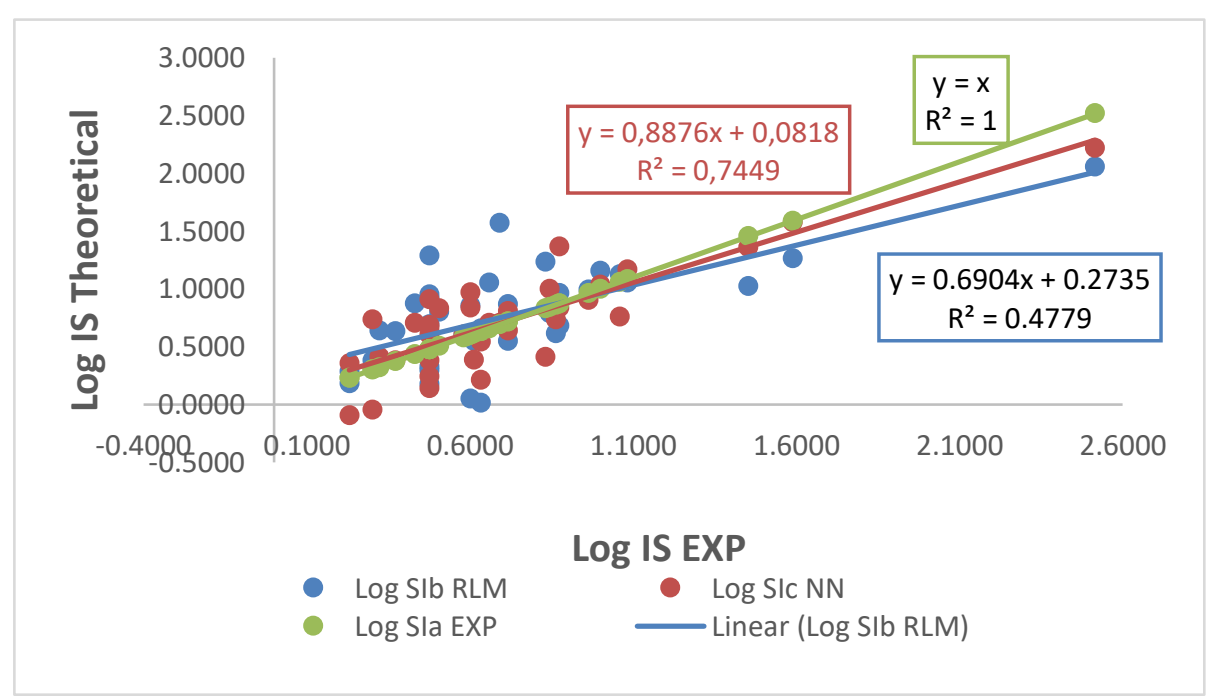

Figure 7. Correlation between experimental SI and theoretical SI using RLM and NN.

3.2. ADMETlab study.

2D-QSAR analyzed the series of molecules to determine the most reliable molecule, and this one will be studied by ADMET prediction to understand better its cost-effectiveness in the development of new drugs[41].

ADMET properties with active molecules were called in Table 5 and Figure 9.

Table 5. In silico ADMET prediction of active molecule (compound 9).

\begin{tabular}{|c|c|c|c|c|c|}
\hline Absorption & $\begin{array}{l}\text { Favorable/unfa } \\
\text { vorable }\end{array}$ & distribution & $\begin{array}{l}\text { Favorable } \\
\text { /unfavorable }\end{array}$ & Excretion & value \\
\hline Caco-2permeability : -5.001 & favorable & PDB : $95.55 \%$ & unfavorable & $\mathrm{Cl}$ & 2.1 .3 \\
\hline Permeability MDCK : $1.4 \mathrm{e}^{-0.5}$ & favorable & VD $: 0.787$ & Favorable & $\mathrm{T}_{1 / 2}$ & 0.276 \\
\hline Inhibitor Pgp : & favorable & $\begin{array}{l}\text { Penetration BBB : } \\
--\end{array}$ & Favorable & $* * * * * * * *$ & $* * * * * * *$ \\
\hline $\begin{array}{ll}\text { Substrat Pgp : } \quad--- \\
\end{array}$ & favorable & $\mathrm{Fu}: 7.045 \%$ & Favorable & $* * * * * * * *$ & $* * * * * * *$ \\
\hline : $\quad+$ & unfavorable & $* * * * * * * * * * *$ & $* * * * * * * * * * * *$ & $* * * * * * * *$ & $* * * * * * *$ \\
\hline : $\quad$--- & favorable & $* * * * * * * * * * *$ & $* * * * * * * * * * * *$ & $* * * * * * * * *$ & $* * * * * * *$ \\
\hline : $\quad---$ & favorable & $* * * * * * * * * * *$ & $* * * * * * * * * * * *$ & $* * * * * * * * *$ & $* * * * * * *$ \\
\hline
\end{tabular}






Figure 8. Properties physico-chemical obtained by ADMET analysis

Table 6. Drug-likeness prediction of the active molecule based on Lipinski, Ghose, Veber, Egan, and Muegge, bioavailability, and their synthetic accessibility.

\begin{tabular}{l|l|l|l|l|l|l|l} 
& Lipinski & Ghose & Veber & Egan & Muegge & $\begin{array}{l}\text { Bioavailability } \\
\text { score }\end{array}$ & $\begin{array}{l}\text { Synthetic } \\
\text { accessibility }\end{array}$ \\
\hline Compound 9 & yes & yes & No & No & No & 0.55 & 3.68
\end{tabular}

Based on the results shown in Table 6, at the level of absorption, C9 is favorable for Caco-2 permeability and also inhibitory of P-glycoprotein (Pgp). Distribution (VDs) is considered high if the value is greater than 0.45 . The results obtained in Table 5 show that the absorption by Permeability MDCK is favorable since its distribution is about 0.787 , which indicates that VD is favorable. For the blood-brain barrier penetration (BBBp) and the fraction unbound in plasma $(\mathrm{Fu})$ are greater than 0.3 , where the meaning of $\mathrm{C} 9$ is also favorable. Moreover, C9 inhibitor for CYP2C9, however not inhibitor for CYP1A2, CYP2C19, and CYP3A4.

\subsection{Docking molecular.}

The interaction between the amino acids of the active site of the 6LHA protein [42] and the inhibitors to form a stable complex is carried out using the PyRx software [43] and in a box of known parameters specify the surface of the calculations. The formation of a stable complex 
depends on the binding of the inhibitor in the active site. Figure 9 presented below shows that compound 9 takes the shape of the cavity of the protein formed by the residues of the active site, which means that there are interactions that stabilize the complex and, subsequently, a better binding of this compound at the active site. The interactions between the active site of the protein and the two ligands are calculated during the molecular docking, and they are presented in the following table 7.

Table 7. Molecular docking results of the two inhibitors with enterovirus

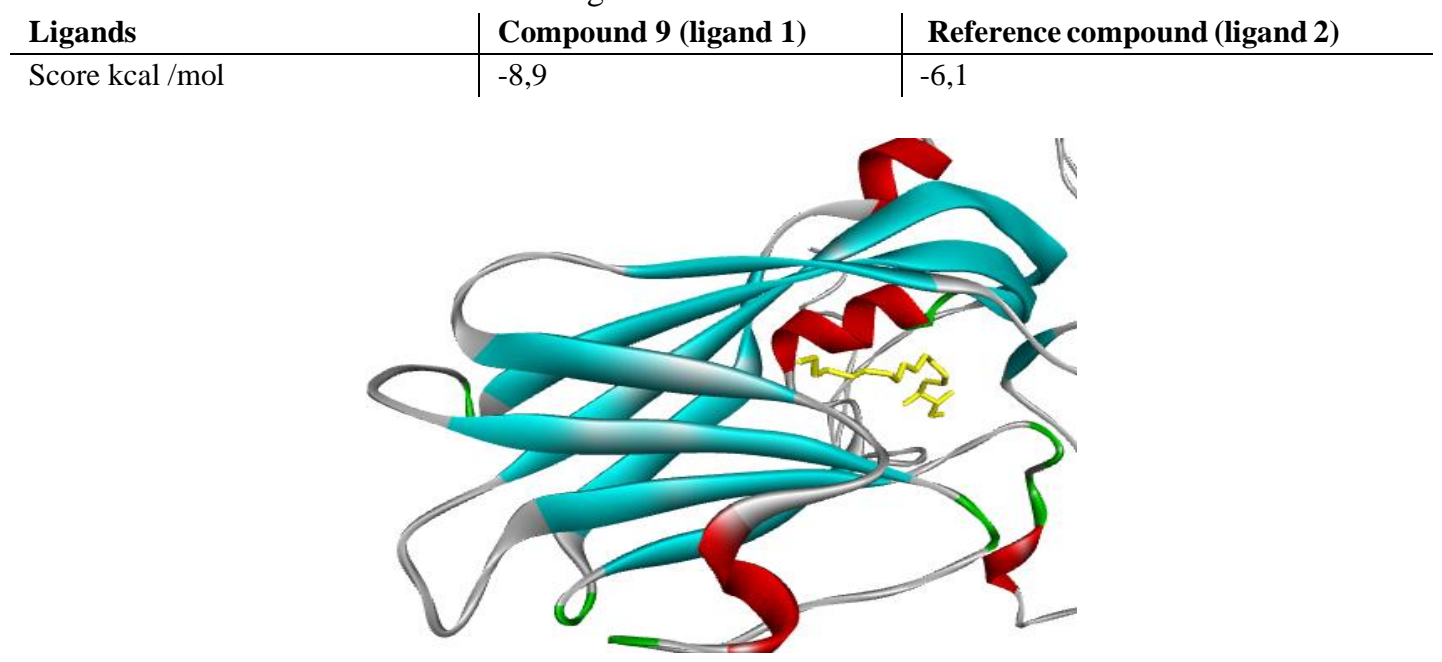

Figure 9. Inhibitor-enzyme complex stored under the pdb extension is visualized in the Discovery Studio software

This study shows that the energies of the complexes protein-Ligand 1 and proteinLigand 2 are respectively $-8.90 \mathrm{Kcal} / \mathrm{mol}$ and $-6.10 \mathrm{Kcal} / \mathrm{mol}$. Thus compound 9 is a better inhibitor than the Control compound. Compound 9 has a hydroxyl group at the end of the side chain of the ligand and therefore can form hydrogen bonds, strong bonds, with the amino acids of the active site of the protein (Figure 10).

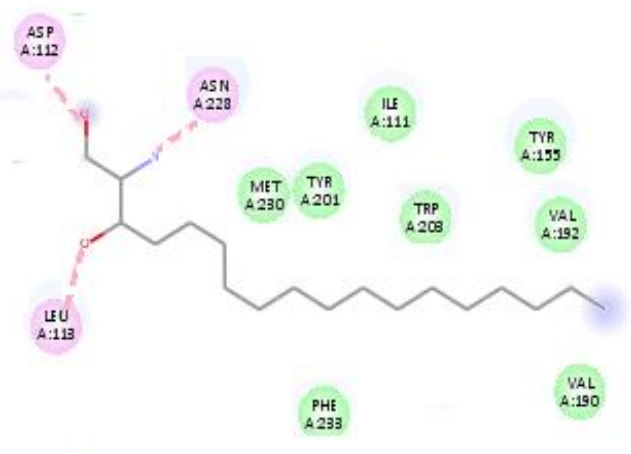

Interactions

Van der Waals

Conventional Hydrogen Bond

Figure 10. The image shows the co-crystallized ligand in three dimensions in the P38alpha active site.

The purpose of this step is to visualize the different amino acids responsible for the active site, so TYR155, ILE 111, TYR201, MET230, TRP208, VAL192, VAL190, and PHE233 represent WDW interactions. In contrast, the rest of the amino acids make electrostatic interactions, this is well illustrated in Figure 11, these amino acids are LEU113, ASP 112 and ASN 228. 

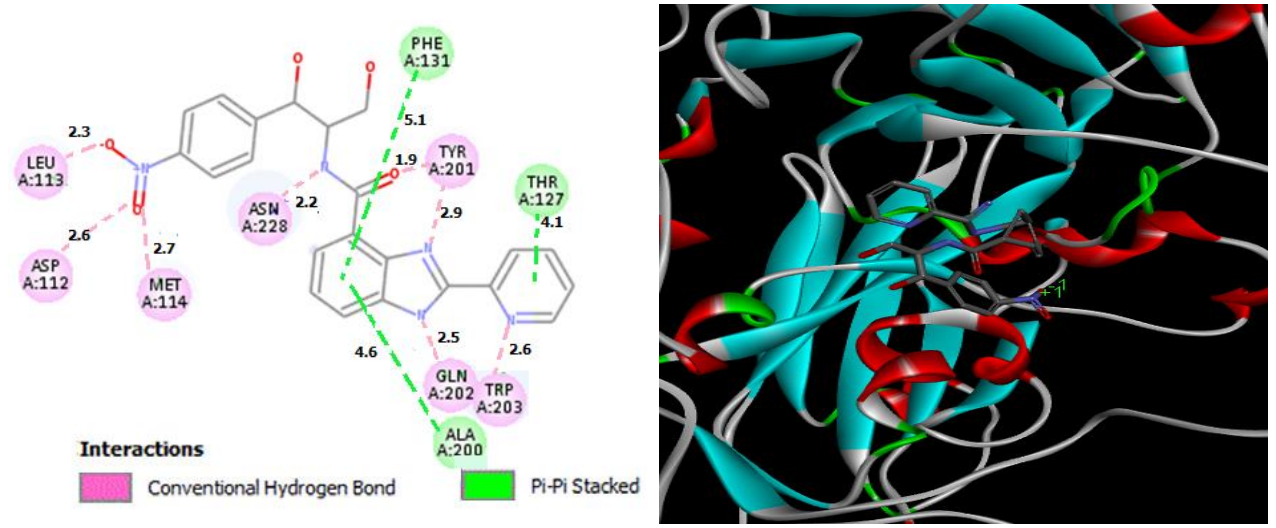

Figure 11. Binding mode of compound 34 with protein. H-binding interactions are shown as dashed lines. This figure was made using Discovery Studio 3.5

Compared to the reference protein complex, compound 9 interacts with the amino acids included in the above-mentioned active site, with other amino acids, most of which are linked to this site by hydrogen.

Table 8. Different interactions between compound 9 and the protein.

Compound 9-protein complex

\begin{tabular}{|c|c|}
\hline H-bond & Pi-pi Stacked \\
\hline LEU $113\left(2.3 \mathrm{~A}^{\circ}\right)$ & ALA $200\left(4.6 \mathrm{~A}^{\circ}\right)$ \\
\hline $\operatorname{ASP} 112\left(2.6 A^{\circ}\right)$ & THR $127\left(4.1 \mathrm{~A}^{\circ}\right)$ \\
\hline MET 114(2.7A $)$ & PHE $131\left(5.1 \mathrm{~A}^{\circ}\right)$ \\
\hline ASN $228\left(2.2 A^{\circ}\right)$ & \\
\hline GLN $202\left(2.5 \mathrm{~A}^{\circ}\right)$ & \\
\hline $\operatorname{TRP} 203\left(2.6 A^{\circ}\right)$ & \\
\hline TYR 201 $\left(2.9 \mathrm{~A}^{\circ}\right)$ & \\
\hline
\end{tabular}

From Table 8 and Figure 11, compound 9 showed a strong interaction with the active site with 7 hydrogen bonds versus 3 bonds for reference; the majority of reference-protein interactions are weak $\mathrm{VdW}$ interactions, confirming the effectiveness of compound 9 against this type of virus.

\section{Conclusions}

In order to produce new drugs effective against enteroviruses, a predictive QSAR study was performed to build a mathematical model relating physicochemical factors (descriptors) to biological activity. The series of bioactive molecules used for this purpose showed strong activity against enteroviruses, in particular compound 9. The model is based on multiple linear regression, neural networks, and cross-validation. Molecular docking revealed that compound 9 has very high interaction affinities against enterovirus A16. The EMR and toxicity suggest that this compound has a good drug property.

QSAR, molecular docking, and ADMET are combined to give potential leads against enteroviruses. Thus, the identification, design, and development of this information can be exploited to diversify the sources of potent benzimidazole drugs.

\section{Funding}

This research received no external funding. 


\section{Acknowledgments}

This research has no acknowledgment.

\section{Conflicts of interest}

The authors declare that they have no conflicts of interest to declare.

\section{Reference}

1. Wang, M.; Han, X.; Zhou, Z. New substituted benzimidazole derivatives: a patent review (2013 - 2014). Expert Opinion on Therapeutic Patents 2015, 25, 595-612, https://doi.org/10.1517/13543776.2015.1015987.

2. Moreira, J.B.; Mann, J.; Neidle, S.; McHugh, T.D.; Taylor, P.W. Antibacterial Activity of Head-to-Head BisBenzimidazoles. Int. J. Antimicrob. Agents 2013, 42, 361-366, https://doi.org/10.1016/j.ijantimicag.2013.04.033.

3. Jasovský, D.; Littmann, J.; Zorzet, A.; Cars, O. Antimicrobial resistance-a threat to the world's sustainable development. Upsala Journal of Medical Sciences 2016, 121, 159-164, https://doi.org/10.1080/03009734.2016.1195900.

4. Li, Z.-J.; Zhang, W.-J.; Bi, W.-Z.; Ma, Q.-J.; Feng, S.-X.; Chen, X.-L.; Qu, L.-B. An Amino-Substituted 2(2'-Hydroxyphenyl) Benzimidazole for the Fluorescent Detection of Phosgene Based on an ESIPT Mechanism. RSC Adv. 2021, 11, 10836-10841, https://doi.org/10.1039/D1RA00811K.

5. Gaba, M.; Mohan, C. Development of Drugs Based on Imidazole and Benzimidazole Bioactive Heterocycles: Recent Advances and Future Directions. Med. Chem. Res. 2016, 25, 173-210, https://doi.org/10.1007/s00044-015-1495-5.

6. Keri, R.S.; Patil, M.R.; Patil, S.A.; Budagumpi, S. A comprehensive review in current developments of benzothiazole-based molecules in medicinal chemistry. European Journal of Medicinal Chemistry 2015, 89, 207-251, https://doi.org/10.1016/j.ejmech.2014.10.059.

7. Tapparel, C.; Siegrist, F.; Petty, T.J.; Kaiser, L. Picornavirus and Enterovirus Diversity with Associated Human Diseases. Infect. Genet. Evol. 2013, 14, 282-293, https://doi.org/10.1016/j.meegid.2012.10.016.

8. Haramoto, E.; Kitajima, M.; Hata, A.; Torrey, J.R.; Masago, Y.; Sano, D.; Katayama, H. A review on recent progress in the detection methods and prevalence of human enteric viruses in water. Water Research 2018, 135, 168-186, https://doi.org/10.1016/j.watres.2018.02.004.

9. Ibba, R.; Carta, A.; Madeddu, S.; Caria, P.; Serreli, G.; Piras, S.; Sestito, S.; Loddo, R.; Sanna, G. Inhibition of Enterovirus A71 by a Novel 2-Phenyl-Benzimidazole Derivative. Viruses 2021, 13, 58, https://doi.org/10.3390/v13010058.

10. Hu, Y.-F.; Jia, L.-P.; Yu, F.-Y.; Liu, L.-Y.; Song, Q.-W.; Dong, H.-J.; Deng, J.; Qian, Y.; Zhao, L.-Q.; Deng, L.; et al. Molecular epidemiology of coxsackievirus A16 circulating in children in Beijing, China from 2010 to 2019. World Journal of Pediatrics 2021, 17, 508-516, https://doi.org/10.1007/s12519-021-00451-y.

11. Perera, D.; Yusof, M.A.; Podin, Y.; Ooi, M.H.; Thao, N.T.T.; Wong, K.K.; Zaki, A.; Chua, K.B.; Malik, Y.A.; Tu, P.V. Molecular Phylogeny of Modern Coxsackievirus A16. Arch. Virol. 2007, 152, 1201-1208, https://doi.org/10.1007/s00705-006-0934-5.

12. Zhu, W.; Liu, Z.; Zheng, X.; Li, J.; Lu, K.; Jiang, X.; Zhang, X.; Ren, F.; Zhang, X.; Xu, J. A Broad and Potent IgM Antibody against Tetra-EV-As Induced by EVA71 and CVA16 Co-Immunization. Vaccine 2021, 39, 6510-6519, https://doi.org/10.1016/j.vaccine.2021.09.056.

13. He, M.; Xu, L.; Zheng, Q.; Zhu, R.; Yin, Z.; Zha, Z.; Lin, Y.; Yang, L.; Huang, Y.; Ye, X. Identification of Antibodies with Non-overlapping Neutralization Sites that Target Coxsackievirus A16. Cell Host \& Microbe 2020, 27, 249-261.e245, https://doi.org/10.1016/j.chom.2020.01.003.

14. Kim, K.-S.; Hufnagel, G.; Chapman, N.M.; Tracy, S. The group B coxsackieviruses and myocarditis. Medical Virology 2001, 11, 355-368, https://doi.org/10.1002/rmv.326.

15. Khalid, D.; Mrabti, N.N. QSAR Study and Molecular Docking of Benzimidazole Derivatives Inhibitors of P38 Kinase. Moroc. J. Chem. 2018, 6, 3511-524, https://doi.org/10.48317/IMIST.PRSM/morjchemv6i3.9273.

16. Kakarla, P.; Inupakutika, M.; Devireddy, A.R.; Gunda, S.K.; Willmon, T.M.; Ranjana, K.; Shrestha, U.; Ranaweera, I.; Hernandez, A.J.; Barr, S. 3D-QSAR AND CONTOUR MAP ANALYSIS OF TARIQUIDAR 
ANALOGUES AS MULTIDRUG RESISTANCE PROTEIN-1 (MRP1) INHIBITORS. Int. J. Pharm. Sci. Res. 2016, 7, 554-572, https://doi.org/10.13040/IJPSR.0975-8232.7(2).554-72.

17. Yi, E.-J.; Shin, Y.-J.; Kim, J.-H.; Kim, T.-G.; Chang, S.-Y. Enterovirus 71 Infection and Vaccines. Clin. Exp. Vaccine Res. 2017, 6, 4-14, https://doi.org/10.7774/cevr.2017.6.1.4.

18. Umare, V.D.; Ingle, V.N.; Wanare, R.K. Synthesis of 2-Substituted-6-Nitro-N-1-_-D Glucopyranosyl Benzimidazoles. International Journal of ChemTech Research 2009, 1.

19. Shao, D.; Yang, Y.; Xue, F.; Luo, X.; Wubulikasimu, R.; Li, Y.; Gao, R.; Ye, W. Design, Synthesis and Inhibitory Properties against Coxsackie B3/B6 of Some Novel Triazole Derivatives. International Journal of Organic Chemistry 2013, 03, 41-46, https://doi.org/10.4236/ijoc.2013.31A005.

20. Huh, H.; Cho, W.; Lee, J.; Noh, Y.; Park, Y.; Ok, S.; Kim, J.; Cho, K.; Lee, H.; Kim, G. 13.2 A 1Tb 4b/Cell 96-Stacked-WL 3D NAND Flash Memory with 30MB/s Program Throughput Using Peripheral Circuit Under Memory Cell Array Technique. 2020, pp. 220-221, https://doi.org/10.1109/ISSCC19947.2020.9063117.

21. Hasanah, A.N.; Soni, D.; Pratiwi, R.; Rahayu, D.; Megantara, S.; Mutakin Synthesis of Diazepam-Imprinted Polymers with Two Functional Monomers in Chloroform Using a Bulk Polymerization Method. J. Chem. 2020, e7282415, https://doi.org/10.1155/2020/7282415.

22. Çerçi, K.N.; Hürdoğan, E. Comparative study of multiple linear regression (MLR) and artificial neural network (ANN) techniques to model a solid desiccant wheel. International Communications in Heat and Mass Transfer 2020, 116, 104713, https://doi.org/10.1016/j.icheatmasstransfer.2020.104713.

23. Zheng, X.; Jiang, Z.; Ying, Z.; Song, J.; Chen, W.; Wang, B. Role of Feedstock Properties and Hydrothermal Carbonization Conditions on Fuel Properties of Sewage Sludge-Derived Hydrochar Using Multiple Linear Regression Technique. Fuel 2020, 271, 117609, https://doi.org/10.1016/j.fuel.2020.117609.

24. Peng; Li, J.; Wang, J.; Zhang, X.; Zhai, H. Investigations of FAK Inhibitors: A Combination of 3D-QSAR, Docking, and Molecular Dynamics Simulations Studies. J. Biomol. Struct. Dyn. 2018, 36, 1529-1549, https://doi.org/10.1080/07391102.2017.1329095 .

25. Ko, T.W.; Finkler, J.A.; Goedecker, S.; Behler, J. A Fourth-Generation High-Dimensional Neural Network Potential with Accurate Electrostatics Including Non-Local Charge Transfer. Nat. Commun. 2021, 12, 398, https://doi.org/10.1038/s41467-020-20427-2.

26. DeVore, R.; Hanin, B.; Petrova, G. Neural Network Approximation. Acta Numerica 2021, 30, 327-444, https://doi.org/10.1017/S0962492921000052.

27. Salt, D.W.; Yildiz, N.; Livingstone, D.J.; Tinsley, C.J.J.P.S. The Use of Artificial Neural Networks in QSAR. 1992, 36, 161-170.

28. Wainer, J.; Cawley, G. Nested Cross-Validation When Selecting Classifiers Is Overzealous for Most Practical Applications. Expert Syst. Appl. 2021, 182, 115222, https://doi.org/10.1016/j.eswa.2021.115222.

29. Gholamiangonabadi, D.; Kiselov, N.; Grolinger, K. Deep Neural Networks for Human Activity Recognition With Wearable Sensors: Leave-One-Subject-Out Cross-Validation for Model Selection. IEEE Access 2020, 8, 133982-133994, https://doi.org/10.1109/ACCESS.2020.3010715.

30. Tropsha, A.; Golbraikh, A. Predictive QSAR Modeling Workflow, Model Applicability Domains, and Virtual Screening. Curr. Pharm. Des. 2007, 13, 3494-3504, https://doi.org/10.2174/138161207782794257.

31. Xiong, G.; Wu, Z.; Yi, J.; Fu, L.; Yang, Z.; Hsieh, C.; Yin, M.; Zeng, X.; Wu, C.; Lu, A.; et al. ADMETlab 2.0: an integrated online platform for accurate and comprehensive predictions of ADMET properties. Nucleic acids research 2021, 49, W5-w14, https://doi.org/10.1093/nar/gkab255.

32. Rocha, J.E.; de Freitas, T.S.; da Cunha Xavier, J.; Pereira, R.L.S.; Junior, F.N.P.; Nogueira, C.E.S.; Marinho, M.M.; Bandeira, P.N.; de Oliveira, M.R.; Marinho, E.S. Antibacterial and Antibiotic Modifying Activity, ADMET Study and Molecular Docking of Synthetic Chalcone (E)-1-(2-Hydroxyphenyl)-3-(2,4-Dimethoxy3-Methylphenyl)Prop-2-En-1-One in Strains of Staphylococcus Aureus Carrying NorA and MepA Efflux Pumps. Biomed. Pharmacother. 2021, 140, 111768, https://doi.org/10.1016/j.biopha.2021.111768.

33. Venkatraman, V. FP-ADMET: A Compendium of Fingerprint-Based ADMET Prediction Models. J. Cheminformatics 2021, 13, 75, https://doi.org/10.1186/s13321-021-00557-5.

34. Xiong, G.; Wu, Z.; Yi, J.; Fu, L.; Yang, Z.; Hsieh, C.; Yin, M.; Zeng, X.; Wu, C.; Lu, A. ADMETlab 2.0: An Integrated Online Platform for Accurate and Comprehensive Predictions of ADMET Properties. Nucleic Acids Res. 2021, 49, W5-W14, https://doi.org/10.1093/nar/gkab255.

35. Taslimi, P.; Erden, Y.; Mamedov, S.; Zeynalova, L.; Ladokhina, N.; Tas, R.; Tuzun, B.; Sujayev, A.; Sadeghian, N.; Alwasel, S.H. The Biological Activities, Molecular Docking Studies, and Anticancer Effects of 1-Arylsuphonylpyrazole Derivatives. J. Biomol. Struct. Dyn. 2021, 39, 3336-3346, https://doi.org/10.1080/07391102.2020.1763838. 
36. Cherrak, S.A.; Merzouk, H.; Mokhtari-Soulimane, N. Potential Bioactive Glycosylated Flavonoids as SARSCoV-2 Main Protease Inhibitors: A Molecular Docking and Simulation Studies. PLOS ONE 2020, 15, e0240653, https://doi.org/10.1371/journal.pone.0240653.

37. Sharma, R.; Dhingra, N.; Patil, S. CoMFA, CoMSIA, HQSAR and Molecular Docking Analysis of IononeBased Chalcone Derivatives as Antiprostate Cancer Activity. Indian J. Pharm. Sci. 2016, 78, 54, https://doi.org/10.4103/0250-474X.180251.

38. Pham, T.N.H.; Nguyen, T.H.; Tam, N.M.; Vu, T.Y.; Pham, N.T.; Huy, N.T.; Mai, B.K.; Tung, N.T.; Pham, M.Q.; Vu, V.V. Improving the Accuracy of AutoDock Vina by Changing the Empirical Parameters. ChemRxiv. Cambridge: Cambridge Open Engage 2021, https://doi.org/10.33774/chemrxiv-2021-bhb1j.

39. Cheng, P.; Li, J.; Wang, J.; Zhang, X.; Zhai, H. Investigations of FAK Inhibitors: A Combination of 3DQSAR, Docking, and Molecular Dynamics Simulations Studies. J. Biomol. Struct. Dyn. 2018, 36, 1529-1549, https://doi.org/10.1080/07391102.2017.1329095.

40. Naceiri Mrabti, N.; Elhallaoui, M. QSAR Study and Molecular Docking of Benzimidazole Derivatives as Potent Activators of AMP-Activated Protein Kinase. J. Taibah Univ. Sci. 2017, 11, 18-39, https://doi.org/10.1016/j.jtusci.2016.05.004.

41. Vardhan, S.; Sahoo, S.K. In Silico ADMET and Molecular Docking Study on Searching Potential Inhibitors from Limonoids and Triterpenoids for COVID-19. Comput. Biol. Med. 2020, 124, 103936, https://doi.org/10.1016/j.compbiomed.2020.103936.

42. He, M.Z., Xu, L.F., Zheng, Q.B., Zhu, R., Yin, Z.C., Cheng, T., Li, S.W. 6LHA: The Cryo-EM Structure of Coxsackievirus A16 Mature Virion. 2020, https://doi.org/10.2210/pdb6LHA/pdb.

43. Dallakyan, S.; Olson, A. Small-Molecule Library Screening by Docking with PyRx. Methods in molecular biology (Clifton, N.J.) 2015, 1263, 243-250, https://doi.org/10.1007/978-1-4939-2269-7_19. 